This item was submitted to Loughborough's Research Repository by the author.

Items in Figshare are protected by copyright, with all rights reserved, unless otherwise indicated.

\title{
CFD modelling of meandering channel during floods
}

PLEASE CITE THE PUBLISHED VERSION

http://dx.doi.org/10.1680/wama.2008.161.1.1

PUBLISHER

(c) Thomas Telford Ltd.

VERSION

VoR (Version of Record)

LICENCE

CC BY-NC-ND 4.0

REPOSITORY RECORD

Shukla, Deepak R., and Koji Shiono. 2019. "CFD Modelling of Meandering Channel During Floods". figshare. https://hdl.handle.net/2134/11284. 
This item was submitted to Loughborough's Institutional Repository (https://dspace.lboro.ac.uk/) by the author and is made available under the following Creative Commons Licence conditions.

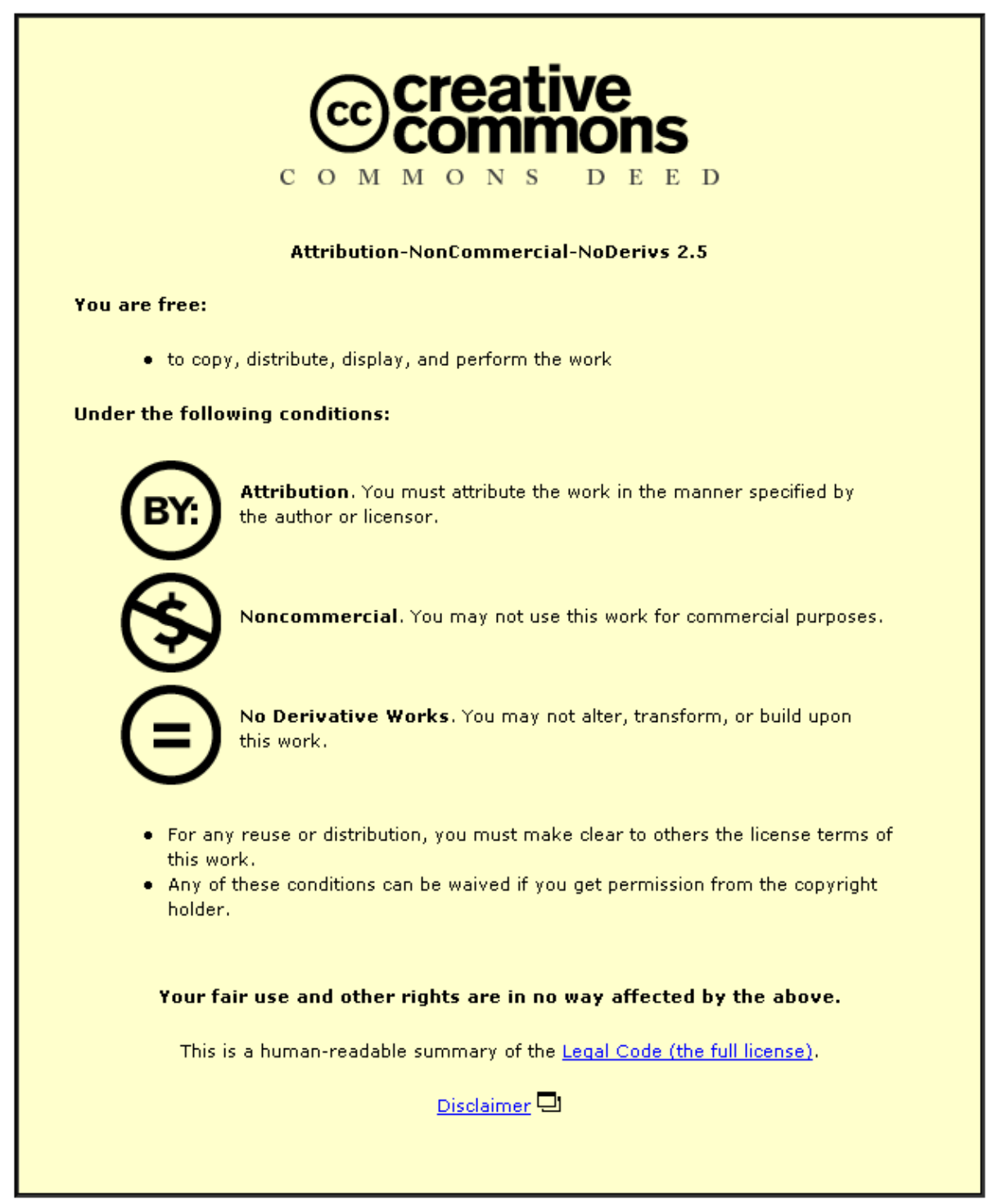

For the full text of this licence, please go to: http://creativecommons.org/licenses/by-nc-nd/2.5/ 


Proceedings of the Institution of
Civil Engineers
Water Management 161
February 2008 Issue WMI
Pages I-12
doi: $10.1680 /$ wama.2008.161.1.I
Paper 700019
Received 07/05/2007
Accepted 07/08/2007
Keywords:
floods \& floodworks/hydraulics \&
hydrodynamics/mathematical
modelling
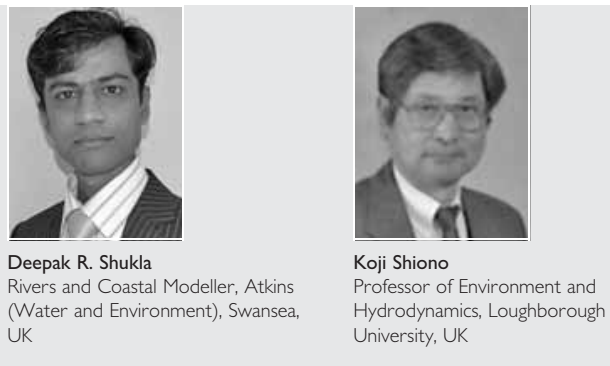

\section{CFD modelling of meandering channel during floods}

D. R. Shukla BE, MTech, PhD and K. Shiono MSc, PhD, CEng, MASCE

The three-dimensional Reynolds-averaged Navier-Stokes (RANS) and continuity equations are solved using a standard computational fluid dynamics (CFD) solver to predict flow in a compound meandering channel. Highquality experimental data from the UK Flood Channel Facility (FCF) are used to validate the computational results. The flow velocities, free-surface elevation, bed shear stress and turbulent kinetic energy are predicted reasonably well. The measured and predicted flows are analysed qualitatively and quantitatively to improve further understanding of mean flow, turbulence and secondary flow structures in a compound meandering channel. The streamwise component of the mean vorticity equation is used to quantify the behaviour of secondary flow circulations in terms of their generation, development and decay along the meandering channel. The turbulent kinetic energy equation is used to understand energy expenditure mechanisms of secondary flow circulations. The numerical results show that one of the shear stresses significantly contributes towards the generation of the streamwise vortex and the production rate of turbulent kinetic energy.

\section{NOTATION}

$B \quad$ main channel top width

$B(x, y) \quad$ bed elevation

$b \quad$ main channel bottom width

$C_{1 \varepsilon} \quad$ constant in $k-\varepsilon=1.44$

$C_{2 \varepsilon} \quad$ constant in $k-\varepsilon=1.92$

$C_{\mu} \quad$ constant in $k-\varepsilon=0.09$

E roughness parameter (law of wall constant)

$F_{i} \quad$ external body force

$H \quad$ total water depth

$h \quad$ main channel depth

$h(x, y, t)$ depth of water

$i, j \quad$ standard tensor indices varying between 1 and 3

$k \quad$ turbulent kinetic energy

$k_{\mathrm{s}} \quad$ equivalent sand-grain roughness height

$L_{\mathrm{c}} \quad$ curved channel length for one meander wavelength

$L_{\mathrm{co}} \quad$ length of the crossover region

$L_{\mathrm{w}} \quad$ meander wavelength

$P \quad$ pressure

$P_{k} \quad$ production rate of turbulent kinetic energy $k$

Re Reynolds number

$R e_{*} \quad$ roughness Reynolds number

$r_{\mathrm{c}} \quad$ average bend radius of curvature $r_{\mathrm{i}} \quad$ inner bend radius of curvature

$r_{0} \quad$ outer bend radius of curvature

$S(x, y, t)$ position of free surface

$s \quad$ sinuosity of main channel $\left(L_{\mathrm{c}} / L_{\mathrm{w}}\right)$

$t \quad$ time

$U_{i} \quad$ mean velocity component in the $x_{i}$ direction

$(i=1,2,3)$

$u_{*} \quad$ shear velocity

$u_{i} \quad$ instantaneous velocity component in the $x_{i}$ direction $(i=1,2,3)$

$-\overline{u_{i}^{\prime} u_{j}^{\prime}} \quad$ turbulent Reynolds stresses

$x, y, z \quad$ Cartesian coordinate direction

$Y^{+} \quad$ non-dimensional distance from wall

$\alpha \quad$ crossover angle

$\Delta z \quad$ distance of first horizontal level above the channel bottom

$\delta_{i j} \quad$ Kronecker delta function

$\varepsilon \quad$ energy dissipation rate

$\theta \quad$ angle of meander bend arc

$\kappa \quad$ von Korman constant $=0 \cdot 41$

$\mu \quad$ molecular viscosity

$\nu \quad$ kinematic viscosity

$\nu_{\mathrm{t}} \quad$ turbulent or eddy viscosity

$\rho \quad$ fluid density

$\sigma_{\varepsilon} \quad$ constant in $k-\varepsilon=1 \cdot 3$

$\sigma_{k} \quad$ constant in $k-\varepsilon=1 \cdot 0$

$\tau_{\mathrm{b}} \quad$ bed shear stress

$\tau_{i j} \quad$ viscous stresses

$\tau_{\mathrm{w}} \quad$ wall shear stress

\section{INTRODUCTION}

Flow mechanisms in compound meandering channels are recognised to be far more complicated than those in compound straight channels. The continuous variation of mean and turbulent flow parameters along a meander wavelength, the shearing of the main channel flow at the bankfull level and the presence of strong helical secondary flow circulations in the streamwise direction are some of the important characteristics of flows in compound meandering channels. ${ }^{1-4}$ The secondary flow circulations are particularly important because they govern the advection of momentum, distort the mean velocity distribution and influence bed shear stress, thus producing complex and three-dimensional (3D) turbulent flow structures. In the case of natural alluvial channels, the secondary flow circulations are also primarily responsible for erosion, deposition and sediment transport. Numerous studies have been conducted on flow mechanisms, 
mixing patterns and the behaviour of secondary flow circulations in compound straight and meandering channels. A full understanding of secondary flow structures still remains far from conclusive however because of the influence of a host of geometrical and flow parameters that have not yet been systematically investigated in detail. The generation, development and decay of secondary flow circulations along a meander bend, qualitative and quantitative analysis of secondary flow circulations, variations in strength of secondary flow circulations along a meander wavelength and the production and dissipation mechanisms of turbulence are some of the research issues addressed in this paper.

A complete set of detailed velocity and turbulence data is required to research the above issues; however, most experimental data in the literature are not generally a comprehensive set, which may be due to the time and cost associated with compiling such measurement data. For example, during the B23 experiment at the UK Flood Channel Facility (FCF), ${ }^{2}$ turbulence measurements were not taken along the meandering channel, without which a detailed analysis of turbulent flow structures along a meandering channel for overbank flow is not possible. Today, numerical/ mathematical modelling is increasingly used by scientists and engineers to study flow in compound meandering channels. ${ }^{5-}$ ${ }^{10}$ In the current paper, computational modelling is adopted to generate detailed velocity and turbulence data for the B23 experiment to bridge a gap in an existing dataset. The results of 3D modelling of flow in a compound meandering channel obtained from a commercially available standard computational fluid dynamics (CFD) code are presented. Quantitative analyses of secondary flows and turbulence along the compound meandering channel using the predicted velocity and turbulence data are given. The findings reported give a step towards a comprehensive understanding of mean flow, turbulence and secondary flow structures in compound meandering channels.

\section{THE UK FLOOD CHANNEL FACILITY (FCF)}

Details of the experimental data collected at the FCF during the series B programme can be found in the work of Sellin et al. ${ }^{2}$ The FCF flume is $60 \mathrm{~m}$ long and $10 \mathrm{~m}$ wide, in which a $48 \mathrm{~m}$ long meandering channel was constructed. The meandering channel was laid for a four-meander wavelength. The main channel is $0 \cdot 15 \mathrm{~m}$ deep, trapezoidal in cross-section with a top width of $1.2 \mathrm{~m}$ and $45^{\circ}$ side bank slopes (Fig. 1). Velocity and turbulence measurements were taken using a two-component laser Doppler anemometer (LDA) system at the main channel apex section only. A miniature propeller meter was used to measure the horizontal velocity components at sections MC1MC11 (see Fig. 1 for section details). The bed shear stress was measured only at the apex section using a Preston tube on the bed.

\section{THREE-DIMENSIONAL HYDRODYNAMIC MODELLING}

\section{I. Governing equations}

The Reynolds-averaged Navier-Stokes (RANS) and continuity equations, together with the transport equations for turbulent kinetic energy $(k)$ and dissipation $(\varepsilon)$ and the free-surface equation were solved using the non-hydrostatic pressure code of Telemac-3D (version 5.4). ${ }^{11,12}$ Telemac $^{13}$ is the suite of computer codes dedicated to the numerical simulation of free-surface flows developed by the Laboratoire National d'Hydraulique, Electricite de France (EDF). The 3D RANS equations for turbulent flows can be written in Cartesian form as

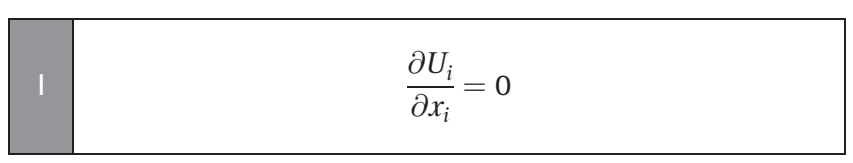

$\begin{aligned} \frac{\partial U_{i}}{\partial t}+\frac{\partial\left(U_{i} U_{j}\right)}{\partial x_{j}}= & -\frac{1}{\rho} \frac{\partial P}{\partial x_{i}}+\frac{\mu}{\rho} \frac{\partial}{\partial x_{j}}\left(\frac{\partial U_{i}}{\partial x_{j}}+\frac{\partial U_{j}}{\partial x_{i}}\right) \\ & +\frac{\partial}{\partial x_{j}}\left(-\overline{u_{i}^{\prime} u_{j}^{\prime}}\right)+F_{i}\end{aligned}$


where $i$ and $j$ represent standard tensor notation indicating the $x, y$ and $z$ coordinate directions, $U_{i}(i=1,2,3)$ is the mean velocity component in the $x_{i}$ direction, $P$ is the pressure, $F_{i}$ is the external body force, $\rho$ is the fluid density, $\mu$ is the molecular viscosity of fluid and $-\overline{u_{i}^{\prime} u_{j}^{\prime}}$ are the turbulent Reynolds stresses modelled as ${ }^{14}$

\begin{tabular}{|l|l|}
\hline 3 & $-\overline{u_{i}^{\prime} u_{j}^{\prime}}=\nu_{\mathrm{t}} \frac{\partial}{\partial x_{j}}\left(\frac{\partial U_{i}}{\partial x_{j}}+\frac{\partial U_{j}}{\partial x_{i}}\right)-\frac{2}{3} k \delta_{i j}$ \\
\hline
\end{tabular}

where $k$ is turbulent kinetic energy, $\delta_{i j}$ is the Kronecker delta function and $\nu_{\mathrm{t}}$ is the turbulent eddy viscosity. The widely used standard $k-\varepsilon$ turbulence model $^{13}$ is applied for calculating eddy viscosity $\nu_{\mathrm{t}}$. The eddy viscosity is related to $k$ and $\varepsilon$ through the Kolmogorov-Prandtl relationship

\begin{tabular}{|c|c|}
\hline 4 & $\nu_{\mathrm{t}}=C_{\mu} k^{2} / \varepsilon$ \\
\hline
\end{tabular}

where $C_{\mu}$ is equal to $0 \cdot 09$. The following transport equations are solved for $k$ and $\varepsilon$.

\begin{tabular}{|l|l|}
\hline 5 & $\frac{\partial k}{\partial t}+U_{i} \frac{\partial k}{\partial x_{i}}=\frac{\partial}{\partial x_{i}}\left(\frac{\nu_{\mathrm{t}}}{\sigma_{k}} \frac{\partial k}{\partial x_{i}}\right)+P-\varepsilon$ \\
\hline
\end{tabular}

\begin{tabular}{|l|l|}
\hline 6 & $\frac{\partial \varepsilon}{\partial t}+U_{i} \frac{\partial \varepsilon}{\partial x_{i}}=\frac{\partial}{\partial x_{i}}\left(\frac{\nu_{\mathrm{t}}}{\sigma_{\varepsilon}} \frac{\partial \varepsilon}{\partial x_{i}}\right)+\left(C_{1 \varepsilon} P_{k}-C_{2 \varepsilon} \varepsilon\right) \frac{\varepsilon}{k}$ \\
\hline
\end{tabular}

where $P_{k}$ is the production rate of $k$

\begin{tabular}{|l|l|}
\hline 7 & $P_{k}=\nu_{\mathrm{t}}\left(\frac{\partial U_{i}}{\partial x_{j}}+\frac{\partial U_{j}}{\partial x_{i}}\right) \frac{\partial U_{i}}{\partial x_{j}}$ \\
\hline
\end{tabular}

The standard values of the model coefficients are $C_{\mu}=0.09$, $C_{1 \varepsilon}=1.44, C_{2 \varepsilon}=1.92, \sigma_{k}=1.0$ and $\sigma_{\varepsilon}=1.3$. The conservative free-surface equation is used to calculate the free-surface position and is written as

\begin{tabular}{|l|l|}
\hline 8 & $\frac{\partial S}{\partial t}+\frac{\partial}{\partial x} \int_{-z}^{S} U \mathrm{~d} z+\frac{\partial}{\partial y} \int_{-z}^{S} V \mathrm{~d} z=0$ \\
\hline
\end{tabular}

where $S(x, y, t)$ is the free-surface elevation, $z(x, y)$ is the bed elevation and $t$ is time.

\subsection{Initial and boundary conditions}

As an initial condition, the water surface profile was set parallel to the channel bed to match the uniform flow profile. Numerical simulations were then carried out using steady state boundary conditions, with constant flow rate prescribed at the inlet and a fixed water depth at the outlet end. For the turbulences' parameter including $k$ and $\varepsilon$, Telemac-3D uses the Dirichlet boundary condition at the inlet. Based on local turbulence equilibrium, $k$ and $\varepsilon$ are

\begin{tabular}{|c|c|}
\hline 9 & $k=\frac{u_{*}^{2}}{\sqrt{c_{\mu}}}, \varepsilon=\frac{u_{*}^{3}}{\kappa k_{\mathrm{s}}}$ \\
\hline
\end{tabular}

For the bottom and lateral solid walls, a slip (friction) boundary condition is used. A standard wall function is applied for the fully turbulent region outside the viscous sub-layer ${ }^{15}$

$$
\frac{U}{u_{*}}=\frac{1}{\kappa} \ln \left(\frac{30 \Delta z}{k_{\mathrm{s}}}\right)
$$

where $U$ is the resultant mean velocity parallel to the wall at the first horizontal mesh level just above the channel bottom, $u_{*}$ is the resultant friction velocity, $\kappa=0 \cdot 41$ is the von Karman constant $\Delta z$ is the distance of the first horizontal level above the channel bottom and $k_{\mathrm{s}}$ is the equivalent sand-grain roughness height. The near-wall values of $k$ and $\varepsilon$ are specified by assuming local equilibrium of turbulence

\begin{tabular}{|l|l|}
\hline I & $k=\frac{u_{*}^{2}}{\sqrt{c_{\mu}}}, \varepsilon=\frac{u_{*}^{3}}{\kappa \Delta z}$ \\
\hline
\end{tabular}

At the outlet boundary, the zero normal gradient boundary condition is set internally for all the flow variables except the water depth. For the free surface, the zero gradient boundary condition is used for all the variables.

\subsection{Finite-element mesh}

A mesh generator within the framework of Telemac-3D was used to generate the mesh. Telemac-3D uses a two-dimensional (2D) mesh as a base mesh to construct the full 3D mesh. The 2D mesh is an unstructured triangular mesh based on Delaunay triangulation. The $3 \mathrm{D}$ mesh is then obtained by duplicating the $2 \mathrm{D}$ base mesh on a number of horizontal planes along the vertical. The main disadvantage of using such a meshing structure is that the deeper region of the domain (e.g. the main channel) is under-discretised and the shallower region (e.g. the floodplain) is over-discretised. The accuracy and economy of the solution therefore lie in selecting the optimum number of horizontal levels bearing in mind the near-wall resolution ( $Y^{+}$criteria) and the computational time. For this study, the $2 \mathrm{D}$ base mesh was built over two meander wavelengths and consisted of 7121 nodes and 13984 triangular elements. The 2D base mesh was then duplicated over 18 horizontal levels along the vertical. Fig. 2 shows a plan view of the 2D base mesh and an elevation view of the 3D mesh.

\subsection{Solution sequence}

For a detailed solution algorithm of the non-hydrostatic code of Telemac-3D, readers are referred to works by Jankowski ${ }^{16}$ and Hervouet and Jankowski. ${ }^{17}$ Telemac-3D is based on a decoupled

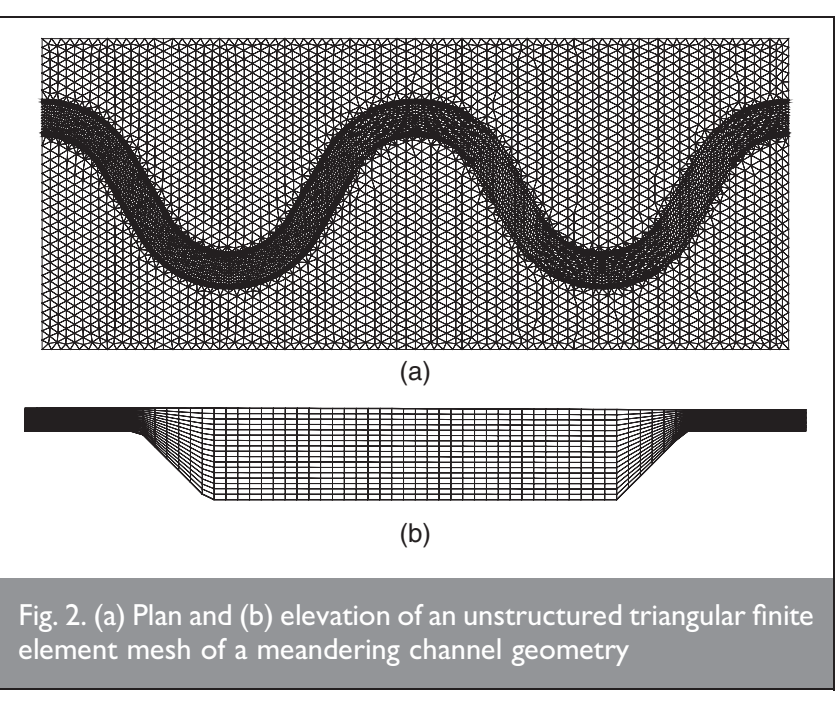




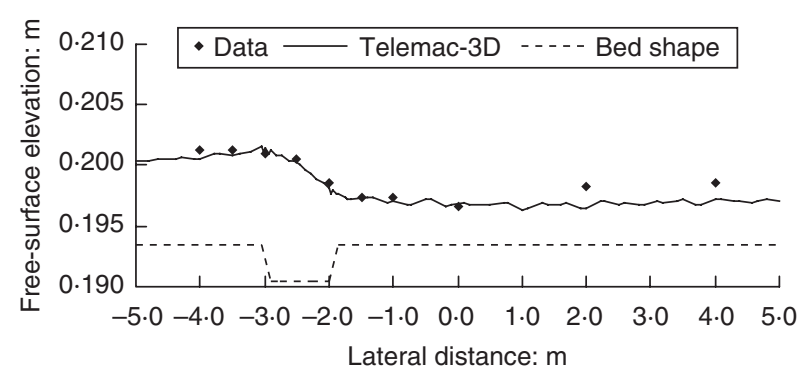

Fig. 3. Measured and predicted free-surface elevation across the apex section

algorithm based on fractional step (operator splitting) techniques in which the governing equations are split into fractional steps and treated using appropriate numerical schemes. This allows the use of different numerical schemes for the advection of flow variables. The semi-implicit streamline upwind Petrov-Galerkin (SUPG) finite element method (EM) ${ }^{18}$ was used for the advection of velocities and water depth. For highly advective flow problems, SUPG obtains a stable solution. The method of characteristics was used for the advection of $k$ and $\varepsilon$. The semiimplicit standard Galerkin FEM was used to solve the diffusive

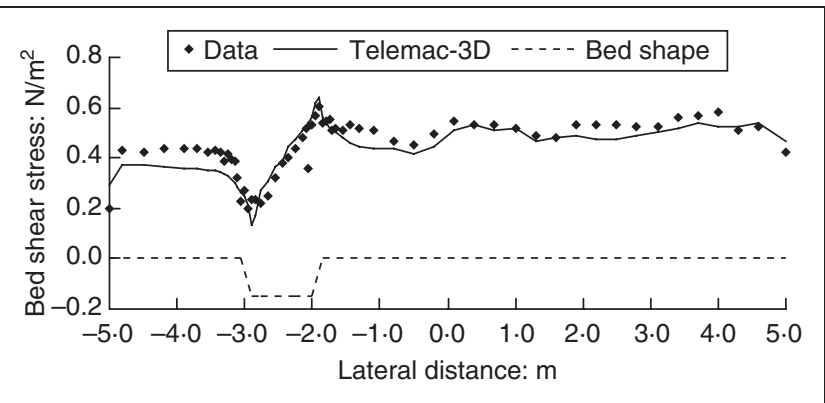

Fig. 4. Measured and predicted bed shear stress at the apex section

terms of the governing momentum equations. The conservative free-surface equation was solved using the semi-implicit SUPG method. The linearised system of equations was solved by an iterative method with an accuracy of $10^{-6}$; the maximum number of sub-iterations allowed was set to 60 , which was not exceeded except for the initial few iterations. Successive calibrations to $k_{\mathrm{s}}$ were carried out to make uniform flow conditions. A calibrated $k_{\mathrm{s}}$ value of $0.00045 \mathrm{~m}$ was used. The solution was assumed to be converged when the mass was balanced within $0 \cdot 5-1 \%$ and the absolute increment values of the
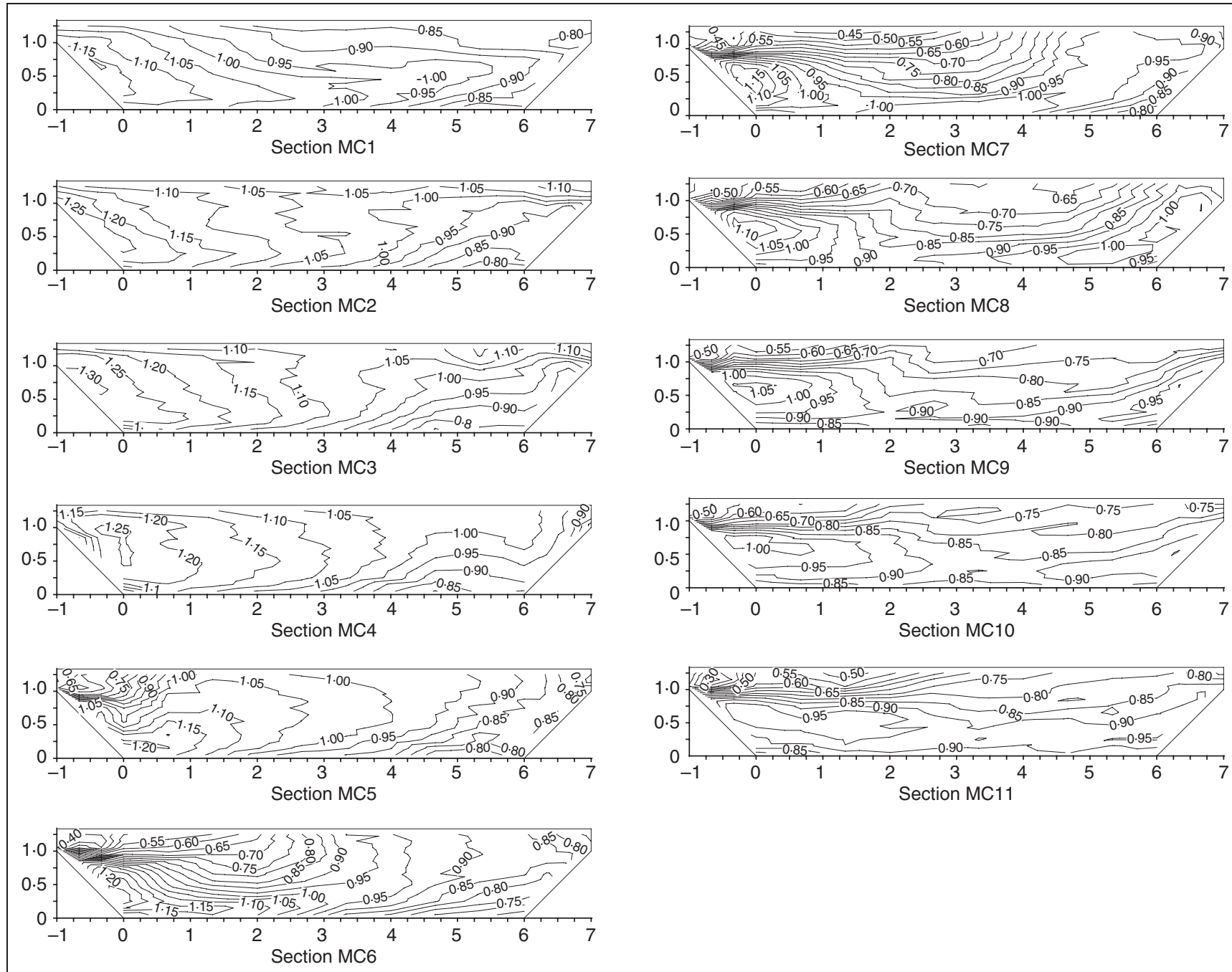

Fig. 5. Isolines of the measured streamwise mean velocity $\mathrm{U} / \mathrm{U}_{\mathrm{S}}$ at sections $\mathrm{MCI}-\mathrm{MCI}$. The horizontal axis represents lateral distance $y / h$ across the main channel and the vertical axis represents the vertical distance $z / h$ ( $h$ is the channel depth at bankfull level, $U_{S}$ is the sectionaveraged velocity) 


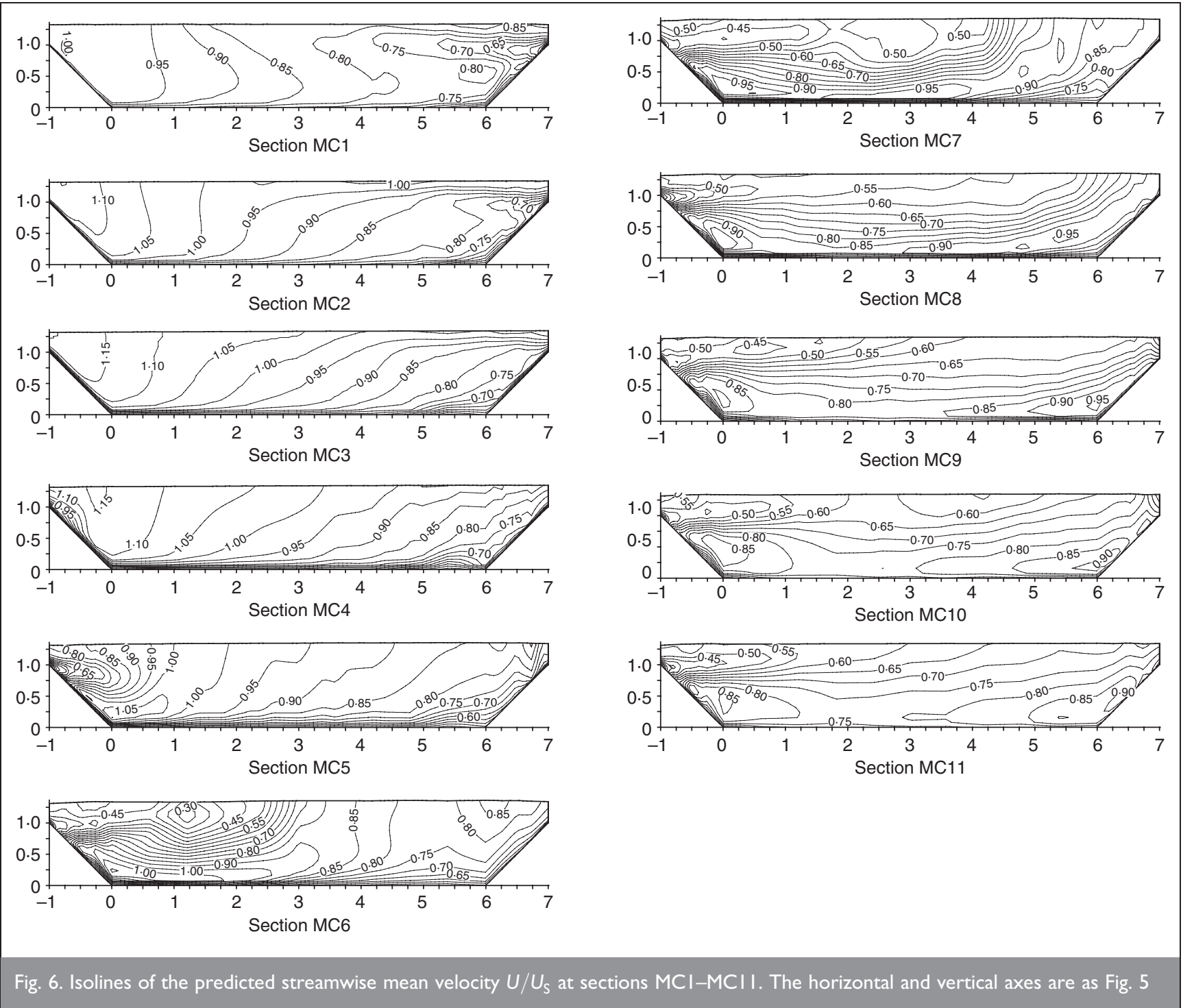

flow variables between the two time steps at all the nodes were below $10^{-4}$.

\section{MODELLING RESULTS-MEAN FLOW ANALYSIS}

\section{I. Free-surface elevations and bed shear stress}

Figure 3 shows the measured and predicted lateral free-surface profile. Reasonably good agreement is obtained in the main channel. The free-surface elevation is under-predicted on the outer floodplain region, particularly outside the meander belt width. Fig. 4 shows a comparison of bed shear stress. The bed shear stress is predicted well, although drops in bed shear stress near $y \sim 0.25 \mathrm{~m}$ are not predicted at all.

\subsection{Mean streamwise velocity}

Figures 5 and 6 show isolines of the measured and predicted mean streamwise velocities $(U)$ at sections MC1-MC11. The streamwise velocity is under-predicted at almost all the sections, although the distribution patterns are reproduced well. The predicted maximum velocity $\left(U_{\max }\right)$ is equal to the sectionaveraged velocity $U_{\mathrm{S}}$ (the measured $U_{\max }$ is $15 \%$ of $U_{\mathrm{S}}$ ) at section MC1 value whereas for MC2 and MC3 it is 10\% (the measured, is 25\%) and 15\% (the measured, is 30\%) higher than $U_{\mathrm{S}}$, respectively. The large gradients of $U$ at the inner bankfull level of the main channel, which is a very important flow phenomenon in terms of the generation of shear layer, are predicted well. In all, the $U$ distribution is predicted fairly well with a consistent under-estimation at all the sections. Similar results were also obtained by others, ${ }^{5-10}$ which may show that there is weakness in using CFD to simulate flow characteristics in a meandering channel.

\subsection{Secondary flow circulations}

To understand the flow behaviour along the half-meander wavelength, secondary flow vectors are plotted at sections 1-13 (see Fig. 1 for the location of sections 1-13). The measured secondary flow circulations are available only at the apex section (section MC3 or section 1), and are shown in Fig. 7. Three anticlockwise circulation cells are seen. The cell near the inner side of the main channel is much stronger than the circulation cell near the outer side of the main channel. A rather

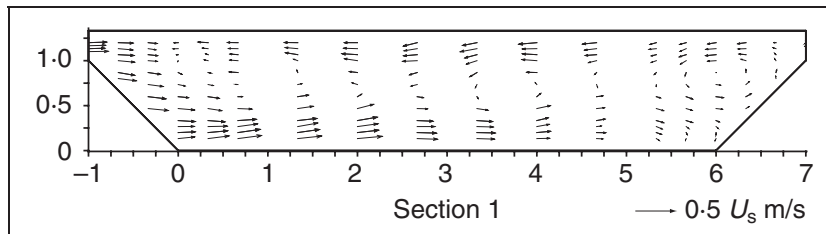

Fig. 7. Measured secondary flow vectors at the apex section. The horizontal and vertical axes are as Fig. 5 


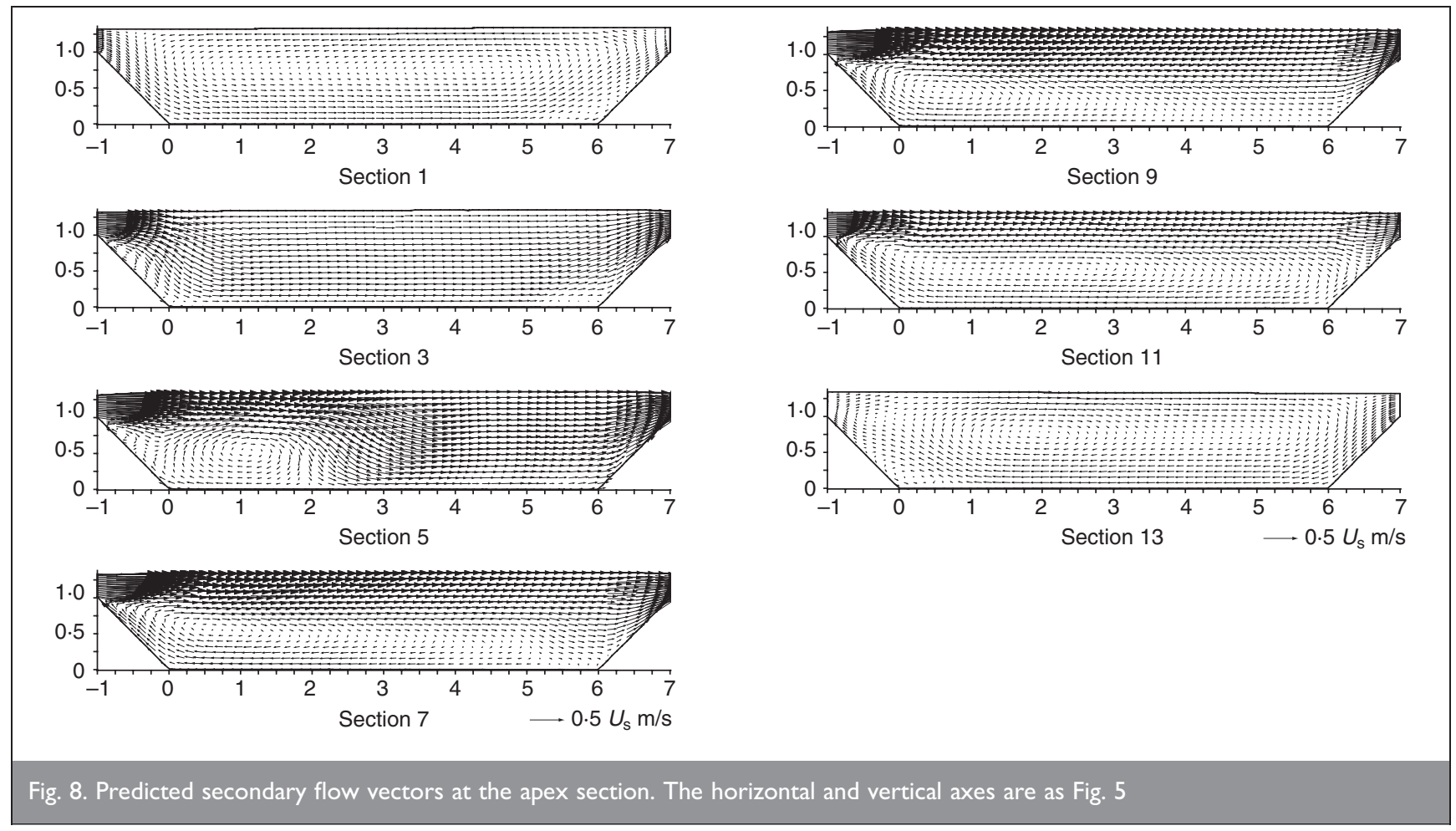

weak and clockwise circulation cell is also seen near the bed at $y / h \sim 5 \cdot 5$.

Figure 8 shows the predicted secondary vectors at sections 1-13. At section 1, the apex, a single dominant anticlockwise circulation cell is predicted and occupies almost the whole main channel area. At around $y / h \sim 6$, a small clockwise circulation cell is predicted, which agrees with the measured data. The magnitude of secondary flow vectors is slightly under-predicted. As the flow moves downstream to section 3, the anticlockwise cell observed at section 1 disappears completely. A new clockwise circulation cell is, however, seen near the inner side (left-hand side) of the main channel. It is thus evident that this new circulation cell originates from somewhere between sections 1 and 3. The generation of this new circulation cell at section 3 coincides well with the shearing of the main channel flow by the floodplain flow, which is clearly seen from the $U$ profile at sections MC4 and MC5 (see Figs 5 and 6). A strong sign of floodplain flow plunging into the main channel can be also seen around $y / h \sim 0.5$. With this and the large gradient of $U$ at around bankfull level near the inner side of the main channel, impingement of the floodplain flow into the main channel is now confirmed. At section 5, the start of the crossover region, the magnitude of floodplain flow entering the main channel increases. At $y / h \sim-0.75$, a small clockwise circulation cell is seen. This may be another new generation of secondary flow due to floodplain flow similar to the circulation cell at section 3. The circulation cell seen at section 3 gains strength and size, and expands towards where the floodplain flow plunges at around $y / h \sim 2 \cdot 5$. This cell occupies most of the main channel below the bankfull level at section 7 (the midcrossover region) where there is still a weak sign of floodplain flow plunging at around $y / h \sim 5 \cdot 8$. At section 9 , the end of the crossover region, the circulation pattern remains almost the same as that at section 7; however, floodplain flow plunging can no longer be seen. This demonstrates that the plunging behaviour of floodplain flow finishes over the crossover section. At section 11, the magnitude of lateral velocity above the bankfull level at the inner side of the main channel is reduced and the secondary flow circulation occupies a larger area than at section 9 and is also weaker. The secondary flow circulation pattern at section 13 returns to that in section 1 but in the opposite sense of rotation.

\section{VORTICITY ANALYSIS (SECONDARY FLOW STRUCTURES)}

The generation mechanisms of secondary flow circulations can be explained by considering the vorticity equation, which can be derived by eliminating the pressure term in the 3D RANS equations through cross-differentiation. The secondary flows in the main channel are 3D; however, the dominant component is the streamwise direction. ${ }^{4,19}$ In this study, therefore, only the streamwise vorticity was analysed to find the main generation mechanisms of the secondary flow using the streamwise vorticity equation. The streamwise component of the vorticity equation can be written as ${ }^{20,21,22}$

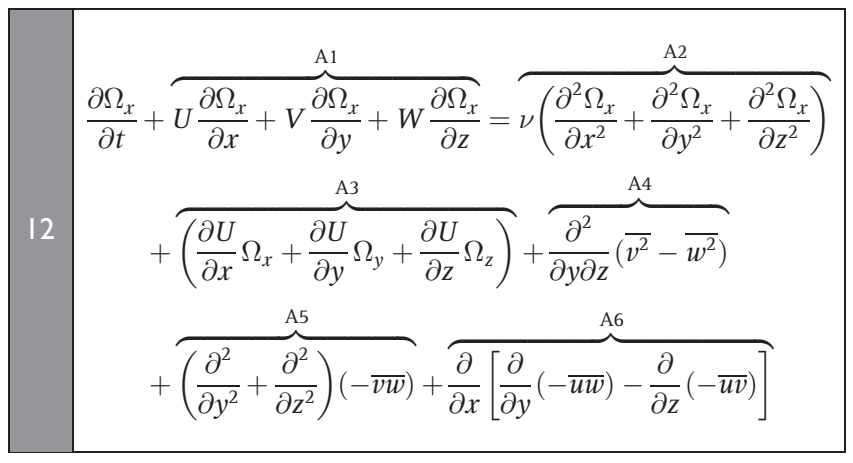

where the mean vorticity components are defined as

$\Omega_{x}=\frac{\partial W}{\partial y}-\frac{\partial V}{\partial z}, \quad \Omega_{y}=\frac{\partial U}{\partial z}-\frac{\partial W}{\partial x}$,
$\Omega_{z}=\frac{\partial V}{\partial x}-\frac{\partial U}{\partial y}$




\section{I. Point of origin of secondary flow circulations}

The secondary flow structure in a compound meandering channel has been illustrated by many researchers by sketching the flow pattern along the meandering channel. The point of origin has not however been investigated yet. Based on study of the point of origin of secondary flow circulations and their generation and decay patterns, geometrical and flow parameters that influence and control the generation of secondary flow circulations can be investigated using the depth-averaged streamwise vorticity $\left(\Omega_{x}\right)$. The depth-averaged streamwise vorticity $\left(\Omega_{x}\right)$ was calculated using the predicted components of velocity in the main channel and is plotted across the main channel at sections 1-13 along the half-meander wavelength in Fig. 9. (A negative value indicates clockwise secondary flow circulation and a positive value means counter-clockwise circulation.)

Figure 9 shows that there are positive and negative values of the depth-averaged streamwise vorticity across section 1 . Negative vorticity values are seen near the edge of the floodplain and the right-hand corner of the main channel, indicating two clockwise circulation cells. The majority of positive values appear in the centre part of the main channel, meaning counter-clockwise circulations as also seen in Fig. 8. There are also three maxima of positive values across the section, which might indicate three counter-clockwise circulations as seen in Fig. 7 and possibly not visible in Fig. 8. At section 3, most positive values in the previous
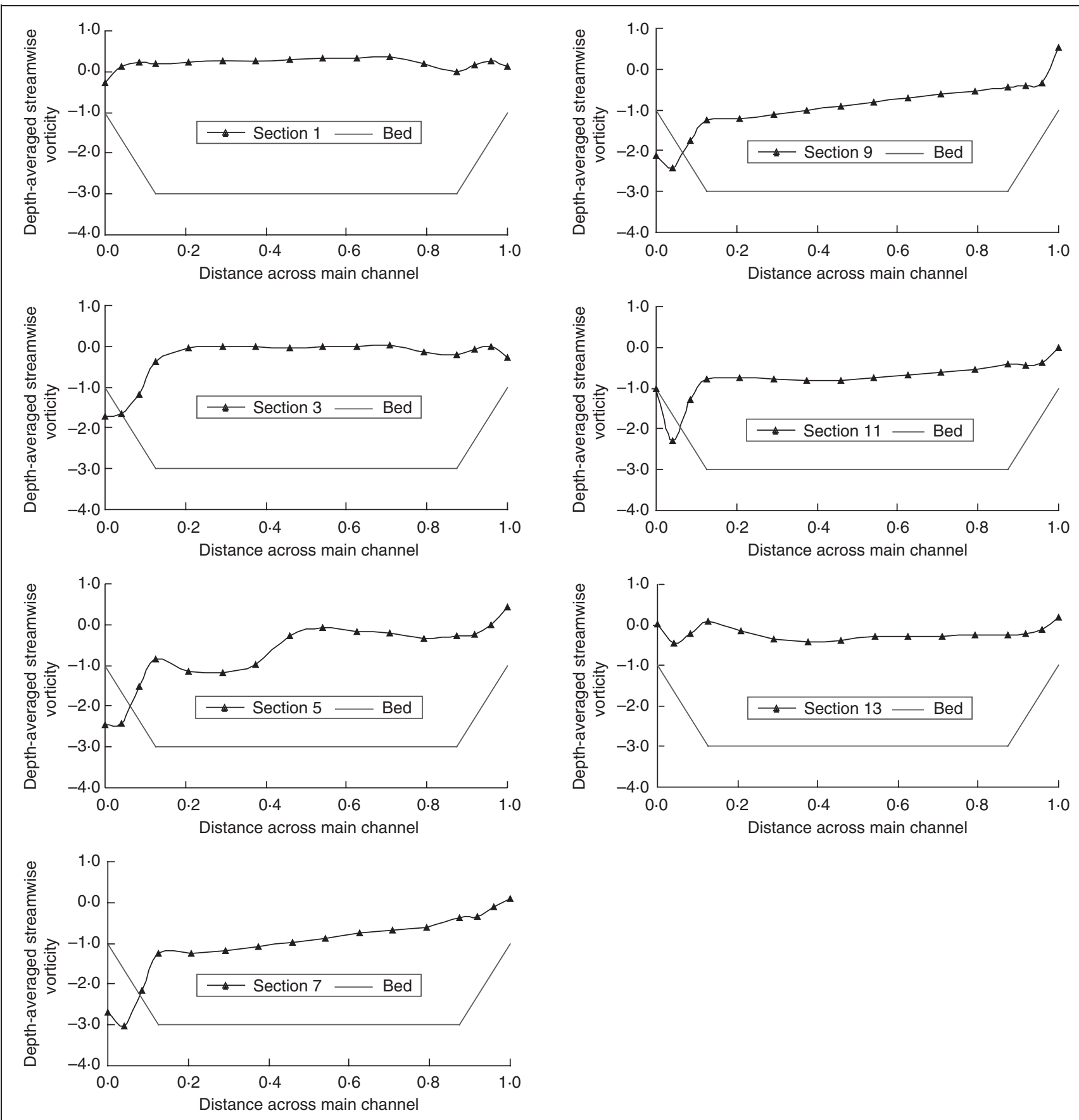

Fig. 9. Predicted depth-averaged streamwise vorticity across the main channel at sections I-I3. The horizontal axis represents lateral distance across the main channel normalised by width of the main channel at bankfull level $(y / B)$. The vertical represents the depth-averaged streamwise vorticity $\left(\Omega_{x}\right)$ normalised by $U_{S} / H$ 
section become nearly zero, which implies the counter-clockwise circulation has disappeared and suggesting the decay of the circulation cells observed at section 1 . There is also a distinctly large negative value in the left-hand corner of the bed, which suggests the formation of a new clockwise circulation. This clockwise circulation gains in size and strength as the flow moves downstream to reach a maximum at section 7 , which is the middle of the crossover region. After section 7, this circulation is weakened over the bend from sections 9-13. The depth-averaged vorticity plots for the seven sections shown in Fig. 9 cannot be used to locate the point of generation of secondary flow circulations; however, it should be between sections 1 and 3 .

From the distribution of positive and negative values of depthaveraged streamwise vorticity across sections, an overall dominant circulation in the main channel can be identified, but its magnitude cannot be determined. To investigate the magnitude of the overall dominant circulation in a cross-section, the streamwise vorticity was averaged over the cross-sectional area and plotted at more sections along the half-meander wavelength in Fig. 10 where the vertical axis represents the mean streamwise vorticity normalised by $U_{\mathrm{S}} / H$ and the horizontal axis represents the distance along the meander bend normalised by the total curved channel length for the half-meander wavelength $\left(L_{c} / 2\right)$.

Figure 10 shows that at $y \sim 0$, which is the apex, $\Omega_{x}$ is positive, meaning domination of counterclockwise secondary flow circulation. Moving downstream along the meander bend, $\Omega_{x}$ decreases and ultimately becomes zero at $y \sim 0.096$. $\Omega_{x}$ then becomes negative, meaning the start of clockwise circulation

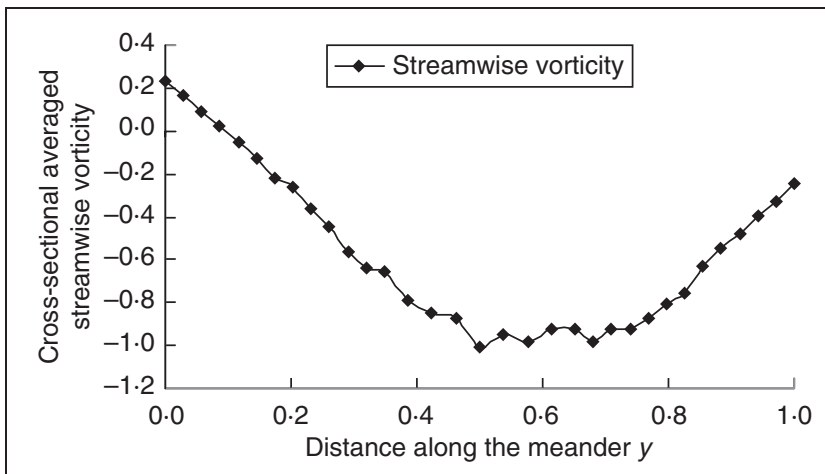

Fig. 10. Predicted cross-sectional averaged streamwise vorticity at sections I-I3. The vertical axis represents the streamwise vorticity normalised by $U_{S} / H . y=0$ represents section I and $y=I$ represents section $\mid 3$

domination, gains strength until the mid-crossover region and remains almost the same until the end of the crossover region. Further downstream, it starts decreasing until the next apex section where the strength of $\Omega_{x}$ is seen to be almost the same as at the upstream apex section. Fig. 10 can be used to locate roughly a generation point of new secondary flow circulation due to floodplain flow in a compound meandering channel. A new secondary flow circulation is generated at a point where its sign changes from positive to negative; in this case new secondary flow circulation starts generating approximately at a bend angle of $16.58^{\circ}$ (between sections 1 and 3 of Fig. 8), which is a considerable distance upstream from the start of the crossover region. This analysis confirms rough illustrations of the
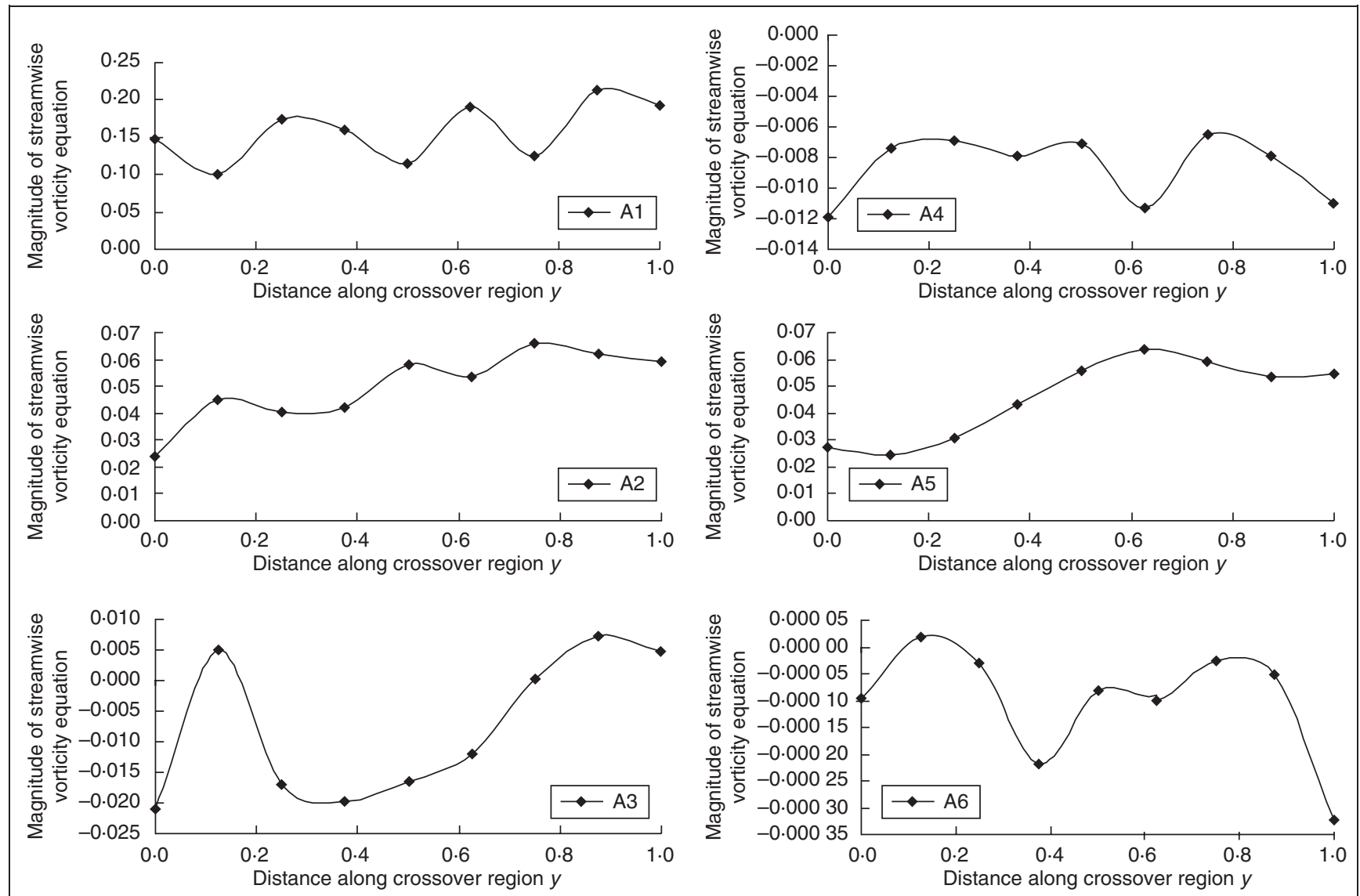

Fig. II. Magnitude (cross-sectional averaged) of terms of the streamwise vorticity equation (equation (I2)) normalised by $\left(U_{S} / H\right)^{2}$ along the crossover. $y=0$ represents section 5 and $y=I$ represents section 9 
generation point of secondary flow in the literature and gives a more precise location.

\subsection{Generation mechanism of secondary flow circulations}

Turbulence-driven secondary flow is significant in a straight compound channel, but no analysis of generation mechanisms in a compound meandering channel was found in the literature. To analyse generation mechanisms of secondary flow due to floodplain flow, the crossover section is chosen where both floodplain flow entering the main channel and shear are strongest; in addition, this is the location of maximum vorticity strength as discussed earlier. To understand the generation mechanisms of secondary flow in the crossover section, each term of the streamwise vorticity $\left(\Omega_{x}\right)$ in equation (12) was calculated as a crosssectional mean using the computational results. All Reynolds stresses were determined using equations (3) and (4). Fig. 11 shows the magnitudes of terms A1, A2, A3, A4, A5 and A6 of equation (12). Term A1, which represents the advection of $\Omega_{x}$, has a very high magnitude-of the order of $10-20 \%$ of $\left(U_{\mathrm{S}} / H\right)^{2}$. Term A2, which represents the viscous damping of $\Omega_{x}$, is smaller than the advection term A1 with a magnitude of $2 \cdot 5-6 \%$ of $\left(U_{\mathrm{S}} / H\right)^{2}$. Term A3, the generation of $\Omega_{x}$ owing to vortex stretching and contraction, is small-around $0 \cdot 5-2 \%$ of $\left(U_{\mathrm{S}} / H\right)^{2}$. For overbank flows, since the generation of secondary flow circulations is not due to centrifugal action as shown earlier, A3 is expected to be small compared with the advection term A1. Term A4 is the production of $\Omega_{x}$ by anisotropy of Reynolds normal stresses. The magnitude of A4 is very small compared with A1-less than $1 \%$ of $\left(U_{S} / H\right)^{2}$. Terms A5 and A6 represent the production of $\Omega_{x}$ by shear stresses $(-\overline{v w})$ and $(-\overline{u v}$ and $-\overline{u w})$, respectively. The magnitude of A5 is $2 \cdot 5-6 \cdot 5 \%$ of $\left(U_{\mathrm{S}} / H\right)^{2}$. The magnitude of A6, which involves gradients of primary shear stresses, is negligibly small relative to all the other terms in the vorticity equation. From this observation it can be inferred that the primary shear stresses $(-\overline{u v}$ and $-\overline{u w})$ do not significantly contribute towards the generation of secondary circulations in compound meandering channels.

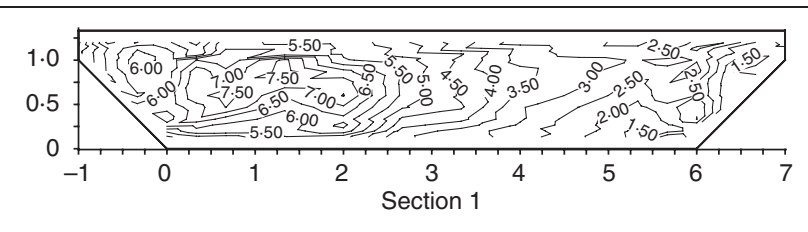

Fig. I2. Isolines of the measured turbulent kinetic energy normalised by $u^{* 2}$ at the apex section. The horizontal and vertical axes are as Fig. 5

From previous research conducted on straight channels, it is established that A4 and A5 are of the same order of magnitude but with opposite signs. Nezu ${ }^{21}$ stated that A4 thus acts to generate secondary flow circulations and A5 suppresses them. In a compound meandering channel, an interesting aspect from the above analysis is that the advection term A1 is the most dominant in terms of magnitude and sink terms A2 and A5, but the source term A3 due to an isotropic turbulence is negligibly small. This suggests that the dominant mechanisms behind secondary flow circulation are the advection term and sink terms in the crossover reach. It can be noticed that when all of the terms are added, the sum is not quite zero. This is due to the effect of the boundary conditions of the crossover reach.

\section{TURBULENCE MECHANISMS}

\section{I. Turbulent kinetic energy}

Figure 12 shows the isolines of the measured turbulent kinetic energy $k$ normalised by $u^{* 2}$ (average friction velocity) at the apex section. A highly turbulent region can be seen towards the inner (left) side of the main channel. The maximum $k$ is around $7 \cdot 5 u^{* 2}$, which is about 50\% higher than $4 u^{* 2}-5 u^{* 2}$ for a simple open channel. ${ }^{21}$

Figure 13 shows the isolines of predicted $k$ at sections $1-13$. At section 1 , the distribution pattern of the predicted $k$ is similar to the predicted single dominant anticlockwise circulation cell
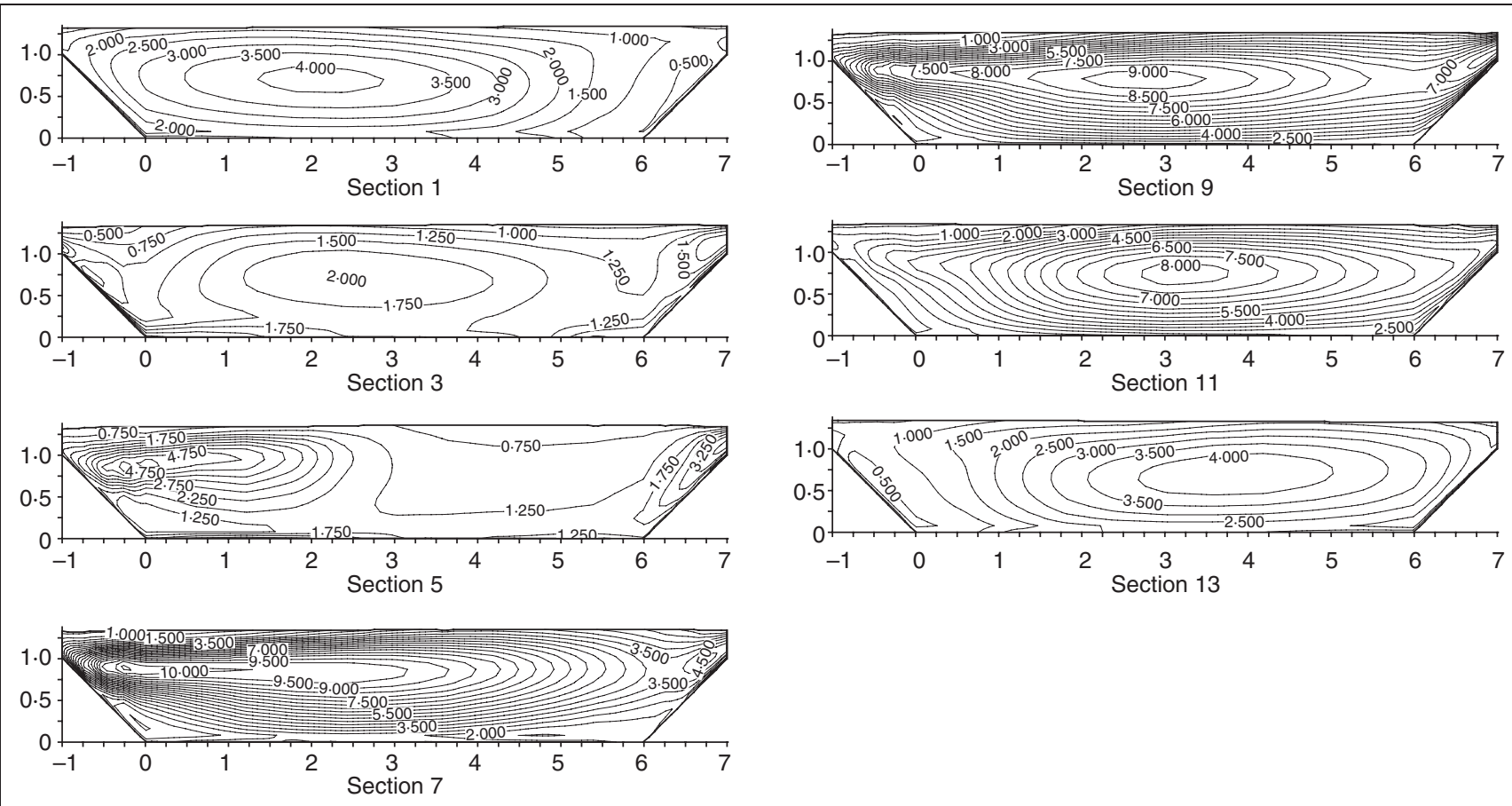

Fig. 13. Isolines of the predicted turbulent kinetic energy normalised by $u^{* 2}$ at sections I-I3. The horizontal and vertical axes are as Fig. 5 
(Fig. 8). The predicted maximum of $k$ is about $4 u^{* 2}$ and is underestimated. The decrease in $k$ towards the outer side of the main channel agrees well with the measurement data and similar results reported previously. At section $3, k$ decreases but the distribution pattern remains similar to that in the previous section. The maximum magnitude of $k$ at section 3 is around $2 u^{* 2}$. The maximum $k$ core is shifted laterally towards the outer side of the main channel. At section 5, the maximum $k$ core is shifted laterally near the outer (right) side of the main channel. A new zone of high $k$ at around bankfull level near the inner (left) side of the main channel is observed. This highly turbulent zone at the inner bankfull level of section 5 is formed due to the shear interaction between the main channel and the floodplain flows, which is much higher than the turbulence generated by the boundary. As the flow travels further downstream to section 7, the high- $k$ zone develops further and extends laterally towards the right-hand side of the main channel. The maximum magnitude of $k$ at section 7 is around $11 u^{* 2}$. At section 9, this highly turbulent region travels further towards the inner side (right-hand side) of the main channel with a maximum $k$ of around $9 u^{* 2}$. At sections 11 and 13, the magnitude of $k$ decreases further. At section 13, the pattern and magnitude of $k$ form a mirror image of section 1. From the $k$ distributions along the meandering channel, all the patterns are very similar to those of the streamwise velocity and secondary flow and the core of $k$ due to floodplain flow mixing and secondary flow shearing being much larger than near boundary.

\subsection{Turbulent kinetic energy budget}

In a simple and compound straight channel, the production of turbulent kinetic energy is mainly from boundary and transverse shear. In the crossover section of a compound meandering channel, however, the boundary shear stress becomes very small compared with the bend section. ${ }^{23}$ To understand whether the production rate of $k$ is mainly from boundary and transverse shear or floodplain flow shear and secondary flow shear, the source term of $k$ over the crossover reach was determined. The source term is $\mathrm{T} 4$ in the following equation

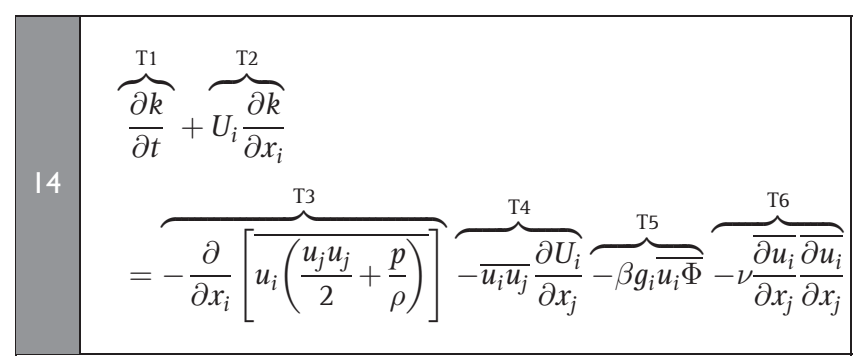

Detailed physical meanings of all the terms can be found in Ref. 14 . Expansion of T4 gives

$$
\begin{array}{|l|l|}
15 & \mathrm{~T} 4=\overbrace{-\overline{u^{2}} \frac{\partial U}{\partial x}}^{\mathrm{P} 1} \overbrace{-\overline{v^{2}} \frac{\partial V}{\partial y}}^{\mathrm{P} 2} \overbrace{-\overline{w^{2}} \frac{\partial W}{\partial z}-\overline{u v}\left(\frac{\partial U}{\partial y}+\frac{\partial V}{\partial x}\right)}^{\mathrm{P} 3} \\
\underbrace{\mathrm{P} 4}_{\text {Total turbulence kinetic energy production (TP) }} & \overbrace{-\overline{u w}\left(\frac{\partial U}{\partial z}+\frac{\partial W}{\partial x}\right)}^{\mathrm{P} 5} \overbrace{-\overline{v w}\left(\frac{\partial V}{\partial z}+\frac{\partial W}{\partial y}\right)}^{\mathrm{P} 6}
\end{array}
$$

Each term in equation (15) was calculated using computational results and plotted along the crossover region in order to understand the production rate of $k$. Fig. 14 shows the rate of production of $k$ by Reynolds normal stresses. The magnitude of P1

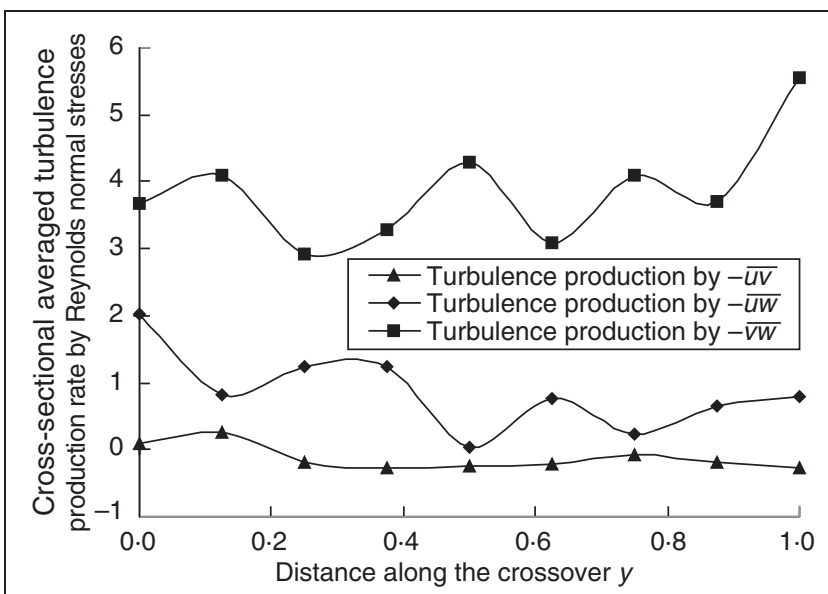

Fig. 14. Comparison of cross-sectional averaged turbulence production rate by Reynolds normal stresses (PI, P2 and P3 of equation (I5)). The vertical axis represents turbulence production normalised by $u^{* 3} /$ H. $y=0$ represents section 5 and $y=$ I represents section 9

is negligibly small compared with P2 and P3, and is negative for most of the crossover region. A negative value means dissipating turbulence. The contribution of $-\overline{w w}$ towards turbulence production is significant compared with $-\overline{u u}$ and $-\overline{v v}$. The average maximum magnitudes of $\mathrm{P} 2$ and $\mathrm{P} 3$ in the crossover region are around $1 u^{* 3} / H$ and $4 u^{* 3} / H$, respectively. Among the normal stresses, $-\overline{w w}$ was found to provide the most significant contribution towards turbulence production rate in the crossover region.

Turbulence production rates in terms of Reynolds shear stresses are shown in Fig. 15. The Reynolds shear stresses contribute towards the production rate much more than Reynolds normal stresses. The magnitude of $\mathrm{P} 4$, which is the contribution of $-\overline{u v}$ to turbulence production, is nearly the same as that of $-\overline{w w}$; however terms P5 and P6 are particularly large in magnitude compared with the other terms. At the start of the crossover region, turbulence production rates due to $-\overline{u w}$ and $-\overline{v w}$ are nearly equal. Moving further downstream along the crossover region, the magnitude of $\mathrm{P} 5$ consistently increases until the end of

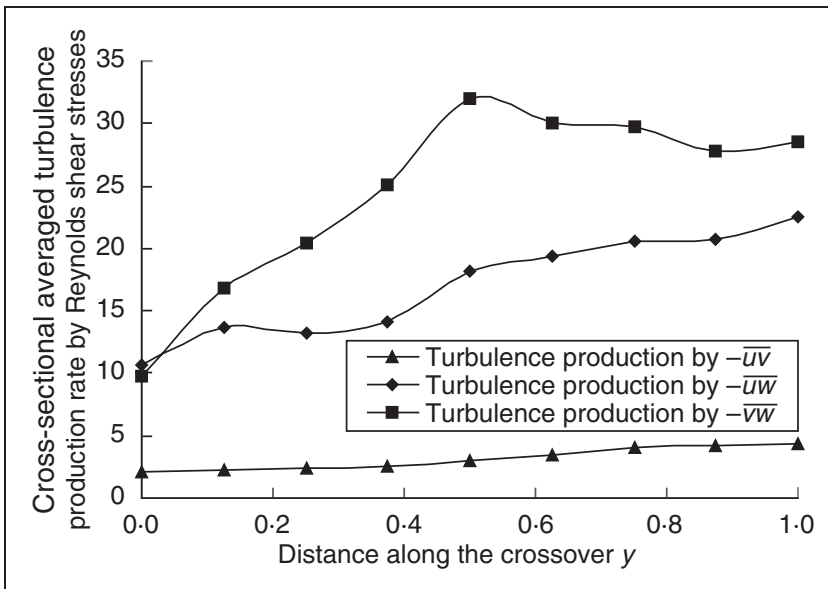

Fig. I5. Comparison of cross-sectional averaged turbulence production rate by Reynolds shear stresses (P4, P5 and P6 of equation (I5)). The vertical axis represents turbulence production normalised by $u^{* 3} / H . y=0$ represents section 5 and $y=1$ represents section 9 


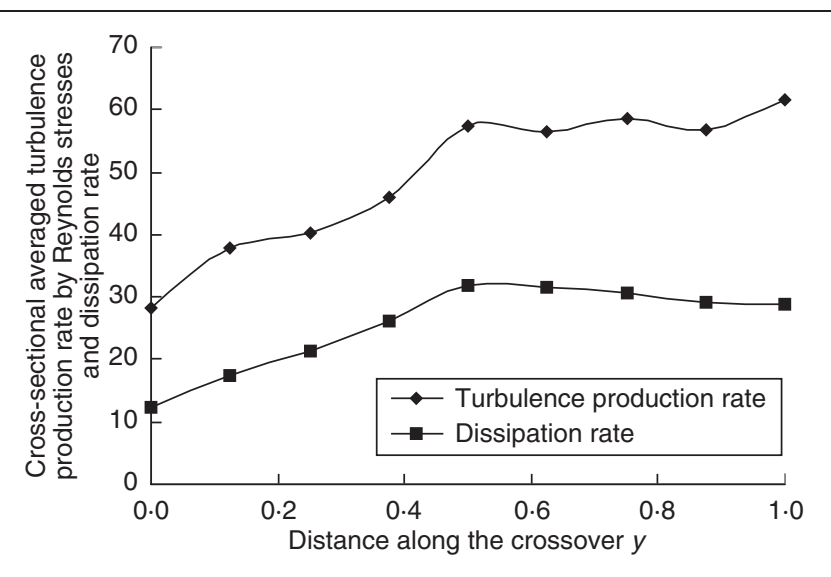

Fig. 16. Comparison of cross-sectional averaged turbulent production rate by Reynolds stresses and viscous dissipation rate. The vertical axes represents turbulence production rate and dissipation rate normalised by $u^{* 3} / H . y=0$ represents section 5 and $y=1$ represents section 9

the crossover region; the magnitude of P6 increases until the mid-crossover region and then starts decreasing gradually. The maximum magnitude of P6 is around $32 u^{* 3} / H$ (i.e. eight times the contribution of the vertical normal stress) near the midcrossover region, after which the magnitude starts gradually decreasing. Since the magnitude of $\mathrm{P} 4$ is considerably smaller than P5 or P6, it can be inferred that the transverse component of Reynolds shear stress is not significant in turbulence production. From the above analysis, it can be concluded that the $k$ production rate is dominated by both secondary flow shear and shear in the vertical direction generated by floodplain flow entering the main channel; the secondary flow shear is, however, larger than that generated by floodplain flow. This agrees with significant energy extraction from the mean flow due to secondary flow as shown in the vorticity analyses. By contrast, in a straight compound channel, the main turbulence production is transverse shear in the shear layer. The generation mechanisms of turbulent kinetic energy are therefore quite different in compound straight and meandering channels. In terms of depth-averaged modelling, it is very important to consider transverse shear (i.e. transverse eddy viscosity) for a straight compound channel, but not important for a compound meandering channel. This also confirms similar results using quasi-2D and 2D models. ${ }^{24,25}$

\subsection{Turbulence production and dissipation}

Turbulent flows are always dissipative due to fluid viscosity. Viscous shear stresses perform deformation work on fluid elements, which increases the internal energy of the fluid at the expense of turbulent kinetic energy. ${ }^{26}$ For turbulence to be sustained, a continuous supply of energy is required from the mean flow. Fig. 16 shows total turbulent kinetic energy production rate due to Reynolds stresses and its dissipation rate due to viscous stresses, where it can be seen that the turbulence production rate is considerably larger than its dissipation rate. This implies that there is more continuous supply of turbulent kinetic energy from the mean flow than its dissipation rate, suggesting that turbulence is eventually advected with mean flow from one point to another with the magnitude governed by the difference of production and dissipation if the diffusion term T3 is relatively small.

\section{CONCLUSIONS}

Three-dimensional CFD modelling was used to predict velocity, secondary flow and turbulent kinetic energy in a compound meandering channel. The patterns of these parameters were reasonably well predicted. The standard $k-\varepsilon$ turbulence model under-predicted the turbulent kinetic energy at the bend apex section when compared with experimental data. Despite the under-prediction of $k$, the mean flow velocities, free-surface elevation and bed shear stress were predicted reasonably well. The standard $k-\varepsilon$ turbulence model utilises several empirical coefficients and constants. These standard values were adopted in this study ${ }^{14}$ this may be causing under-prediction of $k$. A calibration/sensitivity analysis of these coefficients is recommended.

Important flow mechanisms such as shearing of the main channel flow due to floodplain flow plunging into and over the main channel, secondary flow and turbulent kinetic energy were observed through the predicted flow parameters. With the predicted flow parameters, generation mechanisms of secondary flow and turbulence production were analysed. The advection term in the streamwise vorticity equation was found to be the most significant, which implies that generated streamwise vortices are not dissipated fully but are advected downstream with the mean and secondary flows. The secondary shear stress was found to become the significant sink term for the generation of the streamwise vorticity. On the other hand, Reynolds normal stresses, lateral and vertical shear stresses were found to be insignificant in the generation of secondary flow circulations. This is contrary to the situation in compound straight channels where Reynolds normal stresses are important. Reynolds shear stresses induced by floodplain flow and secondary flow were also found to contribute significantly to turbulence production in the crossover section, whereas the contribution of lateral shear stress was found to be negligibly small.

\section{ACKNOWLEDGEMENTS}

D. R. Shukla acknowledges financial support from the Department of Civil and Building Engineering of the Loughborough University to undertake this research. Thanks go to Laboratoire National d'Hydraulique, Electricité de France (EDF) and HR Wallingford, UK for providing a research license for Telemac-3D. The authors are also grateful to Dr P. Rameshwaran (CEH Wallingford, UK), Dr J. M. Hervouet (EDF, France) and all involved in the FCF series of experiments.

\section{REFERENCES}

1. Toebes G. H. and Sooky A. A. Hydraulics of meandering rivers with floodplains. ASCE Journal of Waterways Harbors Division, 1967, 93, No. 2, 1053-1066.

2. Seluin R. H. J., ERvine D. A. and Willetts B. B. The behaviour of two-stage channels. Proceedings of the Institution of Civil Engineers, Water, Maritime and Energy, 1993, 101, No. 2, 99-112.

3. Ervine D. A., Willetts B. B., Seluin R. H. J. and Lorena M. Factors affecting conveyance in meandering compound flows. Journal of Hydraulic Engineering, 1993, 119, No. 12, 1383-1399.

4. Shiono K. and Muto Y. Complex flow mechanisms in compound meandering channels with overbank flow. Journal of Fluid Mechanics, 1998, 376, 221-261. 
5. Morvan H., Pender G., Wright N. G. and Ervine D. A. Three-dimensional hydrodynamics of meandering compound channels. ASCE Journal of Hydraulic Engineering, 2002, 128, No. 7, 674-682.

6. Rameshwaran P. and Shiono K. Computer modelling of twostage meandering channel flows. Proceedings of the Institution of Civil Engineers, Water, Maritime and Energy, 2003, 156, No. 4, 325-339.

7. RAMESHWARAN P. and NADEN P. S. Modelling of turbulent flow in two-stage meandering channels. Proceedings of the Institution of Civil Engineers, Water Management, 2004, 157, No. 3, 159-173.

8. Wilson C. A. M. E., Stoesser T., Olsen N. R. B. and Bates P. D. Application and validation of numerical codes in the prediction of compound channel flows. Proceedings of the Institution of Civil Engineers, Water Management, 2003, 156, No. 2, 117-128.

9. Wormleaton P. and Ewunetu M. Three-dimensional $k-e$ numerical modelling of overbank flow in a mobile bed meandering channel with floodplains of different depths, roughness and planform. Journal of Hydraulic Research, 2006, 44, No. 1, 18-32.

10. Olsen N. R. B. Three-dimensional CFD modelling of self-forming meandering channel. Journal of Hydraulic Engineering, 2003, 129, No. 5, 366-372.

11. Hervouet J.-M. and Van Haren L. Recent advances in numerical methods for fluid flows. In Floodplain Processes (Anderson M. G., Walling D. E. and Bates P. D. (eds)). Wiley, Chichester, 1996, pp. 183-214.

12. Galland J.-C., Goutal N. and Hervouet J.-M. Telemac: a new numerical model for solving shallow water equations. Advances in Water Resources, 1991, 14, No. 3, 138-148.

13. HeRVouet J.-M. TELEMAC modelling system: an overview. Hydrological Processes, 2000, 14, No. 13, 2209-2210.

14. Rodi W. Turbulence Models and Their Application in Hydraulics. Balkema, Rotterdam, 1993.

15. Launder B. E. and Spalding D. B. The numerical computation of turbulent flows. Computer Methods in Applied Mechanics and Engineering, 1974, 3, 269-289.
16. JankowsKi J. A. A Non-hydrostatic Model for Free Surface Flows. PhD thesis, University of Hanover, 1998.

17. Hervouet J.-M. and JANKOWSKI J. Comparing numerical simulations of free surface flows using non-hydrostatic Navier-Stokes and Boussinesq equations. Proceedings of the 4th Conference on Hydroinformatics, Iowa, USA, 2000.

18. Brookes A. N. and Hughes T. J. R. Streamline upwind/Petrov Gakerin formulations for convection dominated flows with particular emphasis on the Navier-Stokes equations. Computer Methods in Applied Mechanics and Engineering, 1982, 32, No. X, 199-259.

19. Willetts B. B. and Hardwick R. I. Stage dependency for overbank flow in meandering channels. Proceedings of the Institution of Civil Engineers, Water Management, 1993, 101, No. 1, 45-54.

20. Demuren A. O. and Rodi W. Calculation of turbulencedriven secondary motion in non-circular ducts. Journal of Fluid Mechanics, 1984, 140, No. X, 189-222.

21. NEZU I. Open-channel flow turbulence and its research prospect in the 21st century. Journal of Hydraulic Engineering, 2005, 131, No. 4, 229-246.

22. NeZu I. and NaKagawa H. IAHR Monograph Series, Turbulence in Open Channel Flows. Balkema, Rotterdam, 1993.

23. Shiono K., Spooner J., Rameshwaran P. and Chandler J. Energy losses in meandering channels with flat and mobile beds for overbank flows. Proceedings of the XXIX IAHR Congress, Beijing, Theme D, 2001, 1, 256-263.

24. Rameshwaran P. and Shiono K. Predictions of velocity and boundary shear stress in compound meandering channel. River Flow 2002, Proceedings of International Conference on Fluvial Hydraulics, Louvain-la-Neuve, Belgium, 2002, 1, 223-231.

25. Rameshwaran P. and Shiono K. Depth-averaged modelling of overbank flow in meandering channels. River Flow 2004, Proceedings of the Second International Conference on Fluvial Hydraulics, Napoli, 2004, 1, 329-335.

26. Tennekes H. and Lumley J. L. A First Course in Turbulence. MIT Press, Cambridge, MA, 1976.

\section{What do you think?}

To comment on this paper, please email up to 500 words to the editor at journals@ice.org.uk

Proceedings journals rely entirely on contributions sent in by civil engineers and related professionals, academics and students. Papers should be $2000-5000$ words long, with adequate illustrations and references. Please visit www.thomastelford.com/journals for author guidelines and further details. 